\title{
Modelling juvenile-mature wood transition in Scots pine (Pinus sylvestris L.) using nonlinear mixed-effects models
}

\author{
Rüdiger MUTZ ${ }^{a *}$, Edith GuILLEY ${ }^{\mathrm{b}}$, Udo H. SAUTER ${ }^{\mathrm{c}}$, Gérard NEPVEU $^{\mathrm{b}}$ \\ a Eidgenössische Technische Hochschule, Zähringerstrasse 24, 8092 Zürich, Switzerland \\ b Équipe de Recherches sur la Qualité des Bois, LERFOB-Laboratoire d'Étude des Ressources Forêt-Bois, UMR INRA-ENGREF 1092, \\ Centre de Recherches de Nancy, INRA, 54280 Champenoux, France \\ ${ }^{\mathrm{c}}$ Institut für Forstbenutzung und Forstliche Arbeitswissenschaft, Universität Freiburg, Werderring 6, 79085 Freiburg i. Br., Germany
}

(Received 27 March 2003; accepted 15 September 2004)

\begin{abstract}
Nonlinear mixed-effects-models are applied successfully to estimate the cambial age of juvenile-mature wood transition in Scots pine sample trees from slow-grown stands. Till now segmented regression models are applied separately for each pith-to-bark-profile of wood density. The nonlinear mixed-effects-model overcomes this limitation while consistently and efficiently estimating the transition point for the whole sample. Furthermore standard errors can be calculated and impacts of stand and tree variables on the shape of pith-to-bark-curves can be tested. Mean ring density, earlywood, and latewood density profiles from 99 trees were determined by X-ray densitometric analysis of disks taken at 4-m stem height. The cambial age of transition from juvenile to mature wood is described according to nonlinear mixed-effects-models based on latewood density profiles. The time-series nature of the data are taken into account. The segmented quadratic-linear model shows the transition at cambial age of 21.77 , which vary with the probability of 0.95 within the interval of $[18.31 ; 26.85]$. Impacts of tree variables or stands on the location of the transition point were not found, but impacts of stands on the shape of pith-to-bark-curves.
\end{abstract}

Pinus silvestris / microdensitometry / nonlinear mixed effects model / pith-to-bark wood density profile / juvenile-adult transition point

Résumé - Modélisation du passage bois juvénile-bois adulte chez le pin sylvestre (Pinus sylvestris L.) à l'aide de modèles mixtes non linéaires. Des modèles mixtes non linéaires ont été utilisés avec succès afin d'estimer l'âge (compté depuis la moelle) du passage bois juvénilebois adulte pour des pins sylvestres provenant de peuplements à croissance lente. Jusqu'à présent, des modèles de régression segmentés étaient ajustés individuellement à chaque profil de densité du bois de la moelle à l'écorce. Le modèle mixte non linéaire permet de dépasser cette limitation en estimant de manière efficace et cohérente l'âge du point de passage pour l'ensemble de la population échantillonnée. En outre, des variances peuvent être estimées et les impacts des peuplements et des caractéristiques des arbres sur la forme des profils de densité du bois de la moelle à l'écorce peuvent être testés. À cette fin, les profils de densité moyenne de cerne, de densité du bois initial et de densité du bois final de 99 arbres ont été mesurés par exploration microdensitométrique de clichés radiographiques obtenus à partir d'échantillons prélevés dans des disques découpés à 4 mètres de hauteur. L'âge compté depuis la moelle du passage bois juvénile-bois adulte a été identifié à partir de modèles mixtes non linéaires appliqués aux profils de densité du bois final. La nature longitudinale des données a été prise en compte. Le modèle segmenté linéaire quadratique retenu permet d'identifier un âge moyen de passage du bois juvénile au bois adulte de 21,77 ans assorti d'un intervalle de confiance à $5 \%$ de 18,31 à 26,85 ans. Si les impacts des variables "caractéristiques des arbres" et "peuplement" sur l'âge de passage bois juvénile-bois adulte n'ont pas été identifiés comme significatifs, le peuplement est apparu avoir un effet sur la forme des courbes d'évolution de la moelle à l'écorce du caractère considéré.

Pinus sylvestris / microdensitométrie / modèle mixte non linéaire / profil de la moelle à l'écorce / passage bois juvénile-bois adulte

\section{INTRODUCTION}

Juvenile wood is one of the most important source of between-tree and intra-tree wood variation, particularly in conifers $[17,25,26]$. Because of the impacts of juvenile wood characteristics on the end products, it is necessary to have an accurate estimation of the proportion and size of juvenile wood core in a tree or sawlog. This allows the separation of juvenile from mature materials, thus minimizing the negative influence on end products [32]. The concept of juvenile wood and its formation is discussed in numerous publications [30, 31, 40]. Juvenile wood forms a central core around the pith from the base up to the top of the tree $[41,42]$ following the crown as it grows. Juvenile wood is found in both softwoods and hardwoods, and is usually of lower quality, especially in conifers, than mature wood. Typically, properties of juvenile wood make

\footnotetext{
* Corresponding author: mutz@gess.ethz.ch
} 
a gradual transition toward those of mature wood. For example in conifers higher ring width, longitudinal shrinkage and grain angle, lower specific gravity, cell length and modulus of elasticity is found in juvenile wood than in mature wood. The proportion of juvenile wood in tree is mainly influenced by genetic factors, tree species, size of growth rings up to a distinct cambial age, and the active live crown. For Douglas-fir and Norway spruce the size and length of the active live crown seems to regulate the quantity and quality of juvenile wood [9, 18].

Therefore the point at which the transition from juvenile to mature wood occurs is a central issue affecting wood quality and product value. However to estimate this boundary with sufficient reliability is difficult.

For one reason some species show indistinct juvenilemature transition zone as spruce (Picea spp.), fir (Abies spp.) and cypress (Cupressus spp.), some show clear transition from juvenile to mature wood as Scots pine, spruce, Douglas-fir and most hard pines [9]. Furthermore the boundary of this zone depends upon the property measured [2]. Variables that have been taken mostly into account are fibre length, fibril angle, longitudinal shrinkage, lignin/cellulose ratio, and wood density. Among all these variables, which are closely connected to end-product quality, wood density play a predominant role. Especially X-ray densitometry, developed by Polge [28], provides a very efficient method to measure pith-to-bark density profiles and to deduce the point of transition from juvenile to mature wood. In the beginning a simple way to determine the transition from juvenile to mature wood was to visually locate the point on the plotted curve, where the increase in density becomes smaller and smaller. The transition point can be quickly and ocularly decided, but if the sample size increases it is rather arduous. No one guarantees for reliability and objectivity. Therefore the research looks for alternatives, especially mathematical-statistical procedures to estimate the demarcation line between juvenile and mature wood. This kind of approach is further supported by successful research on early-wood-latewood transition. Koubaa, Zhang and Makni [16] suggest polynomial solution (inflection point) to estimate the transition from earlywood to mature wood in black spruce instead of the Mork-Index.

Several authors apply segmented regression analysis on the pith-to-bark density profile data in order to estimate the demarcation line: Di Lucca [9], Cook and Barbour [5], Abdel-Gadir and Krahmer [1] for second growth Douglas-fir and Danborg [6] on Norway spruce, Evans et al. [11] for red alder, Bhat et al. [3] for teak, Zhu-Jian et al. [40] for Japanese larch. For the two regions of a tree stem, juvenile (core) and mature (outer), different regression lines will be supposed. With a nonlinear regression analysis the regression parameters of the two regression curves are estimated and simultaneously the point of transition between the two zones [12]. This statistical approach is not limited to certain species as pine or certain kind of data as $\mathrm{X}$-ray densitometry. The application of this method on data from a point dentrometer can also be considered [36].

A serious problem of this approach arises, if the statistical analysis does not take into account the time-series nature of the data. Biased estimates of the regression parameters and the demarcation line are the consequences [33]. Furthermore a problem arises due to the procedure of estimation. The regres- sion analysis was outperformed for each probe (pith-to-bark density profile) separately at the first step, to aggregate the results over all probes in the second. From a statistical point of view this procedure can lead to rather inefficient estimates of the population parameters, because the kind of distribution function of the data and the special estimation procedure for the whole sample are not seriously taken into consideration. In the light of this methodical discussion the present publication offers a statistical method, called nonlinear mixed effectsmodel, which overcomes several disadvantages of the segmented regression analysis, actually suggested in the scientific literature mentioned above:

- efficient and consistent estimation of the parameters and the point of the transition between juvenile and mature wood for the whole sample are possible, based on known distribution functions (f. ex. normal distribution) and estimation procedures (f. ex. Maximum-Likelihood);

- the time-series nature of the data are taken into account (autocorrelations of the residuals);

- estimates of the sample variability of the parameters are given;

- it is possible to test, whether stands or properties of trees (f. ex. d.bh., tree age) have any impact on the sample variability of the parameters, especially the location of the point of juvenile-mature-wood transition.

With nonlinear mixed effects models the scope of the research questions in this scientific area will be expanded. Through the shift from single probes to the whole sample it is not only possible to estimate the juvenile-mature-wood transition out of pith-to-bark density profiles, but also to model within-tree variability and to test the influences of different silviculture regimes on wood density and on points of juvenilemature-wood transition. Mörling [22] found neither an effect of fertilisation nor of thining on ring density of Scots pine in Sweden. Hence this method combines the discussion about juvenile wood with the discussion about modelling of wood density $[8,15,39]$. Whereby mixed effect-model are wide spreaded in wood science, until now nonlinear mixed effects models are only used in wood science for modelling of branchiness $[20,21,35]$.

The objectives of this study are four-folded:

- estimation of the juvenile-mature-wood transition of Scots pine under the condition of autocorrelated residuals;

- estimation of the variability of parameters of the regression parameters for the whole sample;

- testing the impact of stands, d. bh., tree age on pith-to-bark curves;

- simulating pith-to-bark density profiles for different stands, representing different growth conditions.

\section{MATERIALS AND METHODS}

\subsection{Tree sampling}

A total of 99 trees were sampled from five different Scots pine stands in southwest Germany. The stands are typical of the existing resource of this species in the state Rhineland-Palatinate. Four of the 
stands are from the "Pfaelzer Wald" and grow on very poor sites in term of tree-available nutrients and water supply. The fifth stand represents slightly better growth conditions in the Rhine Valley. In both areas the soils are predominantly sandy. Tree age ranged from 70 to $129 \mathrm{yr}$. All trees were dominant or codominant in the stands, and the tree diameter at breast height including the bark ranged from 32 to $35 \mathrm{~cm}$. A rough overview of the average growth rates in the stem at the height $4 \mathrm{~m}$ of the 99 sample trees is given by the following data $(n=8574$ values, aggregated over each year and tree): growth period of cambial age 1-20 yr: $2.38 \mathrm{~mm}$ (range 0.51-4.42 mm); cambial age 21-50 yr: $1.15 \mathrm{~mm}$ (range $0.24-3.47 \mathrm{~mm}$ ); cambial age 51-100 yr: $0.86 \mathrm{~mm}$ (range $0.11-3.08 \mathrm{~mm}$ ). After the first $80-100 \mathrm{yr}$ most sample trees produced very small growth rings in the range of 0.10 to $0.25 \mathrm{~mm}$. This effect can be interpreted as a lack of vigor of the crown caused by changes in water supply and intertree competition. This kind of wood, known as "starved wood", is characterized by very narrow growth rings and small latewood percentages [18].

\subsection{Measurements}

From each tree a 4-cm-thick disk was taken at $4 \mathrm{~m}$ height for analysis of the density variation from pith-to-bark. A height of $4 \mathrm{~m}$ was chosen instead of breast height, because other project objectives required the butt $\log$ to used for lumber test. Other stem heights could not taken into account because of project restrictions. The radial pithto-bark strips for the $\mathrm{X}$-ray densitometry were taken from disk areas free of compression wood, mostly perpendicular to the slope direction of the terrain or to the largest radius of the tree crown.

Density profiles were obtained from each disk using the X-ray densitometer at the Équipe de de Recherches sur la Qualité des Bois of the LERFOB, INRA in Champenoux, France [28, 29]. Density measurements were calibrated to $12 \%$ moisture content (weight at $12 \% \mathrm{MC} /$ volume at $12 \% \mathrm{MC}$ ). Each ring was divided into 20 equal length intervals, each representing 5\% of the ring width, and average density values were computed for each interval. These averages were used in all further analyses as they are more stable than the raw measurements [6]. A comprehensive discussion of possible shortcomings of X-ray densitometry can be found in Schweingruber [34]. In order to do assess both pith-to-bark and intra-ring density profiles, it was necessary to distinguish earlywood from latewood. In addition to the standard definition by Mork [23], which is based on the ratio of cell-wall thickness to lumen diameter, there are two techniques for automatically identifying the earlywood-latewood boundary during the X-ray scanning process. The simplest way is to use a predefined density threshold. A ring-specific threshold was used in this study, computed as the average of the minimum and maximum density values within ring [24]. The data, which are obtained and processed, consist of average values for each growth ring: ring width, mean ring density, earlywood width, earlywood density, latewood width, latewood density.

\subsection{Modelling strategy with nonlinear mixed-effects models}

The first step of the analysis is to select the appropriate density variable in order to determine the transition between juvenile and mature wood for the Scots pine material. The density variables are plotted and visually assessed. If there are any clear differentiation between juvenile and mature wood in one variable, this variable will be used for further analyses. Typically wood density increases from pith to bark with a steep slope in the first 20 years from the pith and a flat slope in the mature wood. To model the juvenile-mature wood transition zone there is a need for two separate regressions to obtain reasonable fits for the whole profile from pith-to-bark. The juvenile part can be described best by a quadratic curve, the mature part regardless of the trend direction by a linear curve. With segmented regression a statistical model is given, which can simultaneously estimate the parameters of the two curves and the breakpoint between juvenile and mature wood $[1,5,9-11,33]$.

The following segmented regression model for $\mathrm{y}_{\mathrm{j}}$ was assumed, whereby $\mathrm{x}_{0}$ is the demarcation line between juvenile and mature wood:

$$
\begin{gathered}
\text { if } \mathrm{x}_{\mathrm{j}}<\mathrm{x}_{0} \\
\mathrm{y}_{\mathrm{j}}=\mathrm{b}_{0}+\mathrm{b}_{1} \mathrm{x}_{\mathrm{j}}+\mathrm{b}_{2} \mathrm{x}_{\mathrm{j}}^{2}+\mathrm{e}_{\mathrm{j}} \quad \mathrm{e}_{\mathrm{j}}=\mathrm{N}\left(0, \sigma_{\mathrm{e}}^{2}\right)
\end{gathered}
$$

otherwise

$$
y_{j}=b_{0}+b_{1} x_{0}+b_{2} x_{0}^{2}+b_{3}\left(x_{j}-x_{0}\right)+e_{j} \quad e_{j}=N\left(0, \sigma_{e}^{2}\right) .
$$

The $\mathrm{x}$-values (age from the pith) ranges for $\mathrm{j}$ from 1 to $\mathrm{k}$. The $\mathrm{x}_{0^{-}}$ value is considered the maximum of the quadratic function:

$$
\mathrm{x}_{0}=-\mathrm{b}_{1} /\left(2 \mathrm{~b}_{2}\right) \text {. }
$$

What was not taken into account until now is the time series nature of the data. The wood formation in one year depends heavily on the wood formation of the year before because of several factors (f. ex. climatic cycles). This time series nature are neglected by several authors, which can lead to biased estimates of the regression parameters and the demarcation line [33]. Therefore the objective of the second step was to find a general time series process that generates most of the individual tree time series using the ARIMA (Autoregressive Integrated Moving average) concept [4]. In the simple case of an autoregressive model of first order $(\operatorname{AR}(1))$, the residuals $e_{j}$ in (2) are autocorrelated as follows:

$$
\mathrm{e}_{\mathrm{j}}=\rho \mathrm{e}_{\mathrm{j}-1}+\varepsilon_{\mathrm{j}} \quad \varepsilon_{\mathrm{j}} \sim \mathrm{N}\left(0, \sigma_{\varepsilon}^{2} \mathbf{I}\right) .
$$

Whereas the procedure described above can be applied only to single pith-to-bark-profiles, nonlinear mixed-effects-models allow to estimate the parameters of the segmented regression and the juvenile and adult transition for the whole sample of pith-to-bark profiles, statistically consistently and efficiently. Therefore the variability of the demarcation line in a sample of $\mathrm{i}=1$ to $\mathrm{N}$ trees can be estimated. The equation (1) can be expanded as follows (model $\mathrm{M}_{2}$ ):

$$
\begin{gathered}
\text { if } \mathrm{x}_{\mathrm{ij}}<\mathrm{x}_{0 \mathrm{i}} \\
\mathrm{y}_{\mathrm{ij}}=\left(\mathrm{b}_{0}+\mathrm{u}_{0 \mathrm{i}}\right)+\left(\mathrm{b}_{1}+\mathrm{u}_{1 \mathrm{i}}\right) \mathrm{x}_{\mathrm{ij}}+\left(\mathrm{b}_{2}+\mathrm{u}_{2 \mathrm{i}}\right) \mathrm{x}_{\mathrm{ij}}^{2}+\mathrm{e}_{\mathrm{ij}}
\end{gathered}
$$

otherwise

$\mathrm{y}_{\mathrm{ij}}=\left(\mathrm{b}_{0}+\mathrm{u}_{0 \mathrm{i}}\right)+\left(\mathrm{b}_{1}+\mathrm{u}_{1 \mathrm{i}}\right) \mathrm{x}_{0 \mathrm{i}}+\left(\mathrm{b}_{2}+\mathrm{u}_{2 \mathrm{i}}\right) \mathrm{x}_{0 \mathrm{i}}^{2}+\left(\mathrm{b}_{3}+\mathrm{u}_{3 \mathrm{i}}\right)\left(\mathrm{x}_{\mathrm{ij}}-\mathrm{x}_{0 \mathrm{i}}\right)+\mathrm{e}_{\mathrm{ij}}$

whereby $\mathrm{u}_{0 \mathrm{i}}, \mathrm{u}_{1 \mathrm{i}}, \mathrm{u}_{2 \mathrm{i}}, \mathrm{u}_{3 \mathrm{i}}, \mathrm{e}_{\mathrm{ij}}$ are random components, which vary randomly over the sample according to a normal distribution with the variances $\sigma_{\mathrm{u} 0}^{2}, \sigma_{\mathrm{u} 1}^{2}, \sigma_{\mathrm{u} 2}^{2}, \sigma_{\mathrm{u} 3}^{2}$ and $\sigma_{\mathrm{e}}^{2}$, whereby the autocorrelation structure for $\mathrm{e}_{\mathrm{ij}}$ (Eq. (2)) will be considered. The parameters $\mathrm{b}_{0}, \mathrm{~b}_{1}, \mathrm{~b}_{2}, \mathrm{~b}_{3}$ build up the fixed-effects-model for the whole sample, which can be tested separately (model $\mathrm{M}_{1}$ ). This nonlinear mixed effects model be estimated by an algorithm proposed by Pinheiro and Bates [27]: In the first step, the $j$ th observation on the $i$ th tree is modelled as

$$
y_{i j}=f\left(\varphi_{i j}, x_{i j}\right)+e_{i j} \quad j=1, \ldots, k_{i}, i=1, \ldots, N
$$

where $\mathrm{f}$ is a nonlinear function of a tree-specific parameter vector $\varphi_{i j}$ and of the predictor $\mathrm{x}_{\mathrm{ij}}, \mathrm{e}_{\mathrm{ij}}$ is a normally distributed noise term with a certain autocorrelation structure. $\mathrm{N}$ is the total number of trees and $\mathrm{k}_{\mathrm{i}}$ is the total number of rings for the disk of tree $i$. In the second step the tree-specific parameter vector is modelled as

$$
\varphi_{\mathrm{ij}}=\mathbf{A}_{\mathrm{ij}} \beta+\mathbf{B}_{\mathrm{ij}} \mathrm{u}_{\mathrm{i}} ; \quad \mathrm{u}_{\mathrm{i}} \sim \mathrm{N}\left(0, \sigma^{2} \mathbf{D}\right)
$$


where $\beta$ is a $p$-dimensional vector of fixed population parameters, $u_{i}$ is a q-dimensional random effects vector associated with the ith tree, $\mathbf{A}_{\mathrm{ij}}$ and $\mathbf{B}_{\mathrm{ij}}$ are design matrices for the fixed and random effects respectively, and $\sigma^{2} \mathbf{D}$ is a (general) variance-covariance matrix. Whether it is worthwhile to apply such complex nonlinear mixed effects models as presented in equation (3) the variability on the two levels "tree" and "pith to bark" has to be estimated, as follows (model $\mathrm{M}_{0}$ ):

$$
\mathrm{y}_{\mathrm{ij}}=\beta_{0}+\mathrm{u}_{0 \mathrm{i}}+\mathrm{e}_{\mathrm{ij}}
$$

with $\mathrm{e}_{\mathrm{ij}}$ follows an autocorrelation process as in equation (2).

Equation (3) is called unconditional nonlinear mixed effects model, because the random factors are estimated without any consideration of factors, which have an impact on the variability of the parameters of the individual model (d.bh, age of the tree,...). If such impact factors $\mathrm{Z}_{\mathrm{ki}}$ are taken into account, equation (3) can be transformed in a conditional model with several impact factors (f. ex. stand effects) on the tree level, represented by interactions terms with parameters on the pith-to-bark-level, as follows with stand as impact factor (model $\mathrm{M}_{3}$ )

$$
\begin{gathered}
\text { if } \mathrm{x}_{\mathrm{ij}}<\mathrm{x}_{0 \mathrm{i}} \\
\mathrm{y}_{\mathrm{ij}}=\mathrm{b}_{0 \mathrm{i}}+\mathrm{b}_{1 \mathrm{i}} \mathrm{x}_{\mathrm{ij}}+\mathrm{b}_{2 \mathrm{i}} \mathrm{x}_{\mathrm{ij}}^{2}+\mathrm{e}_{\mathrm{ij}}
\end{gathered}
$$

otherwise

$$
y_{i j}=b_{0 i}+b_{1 i} x_{0 i}+b_{2 i} x_{0 i}^{2}+b_{3 i}\left(x_{i j}-x_{0 i}\right)+e_{i j}
$$

where

$$
\begin{aligned}
& b_{0 i}=b_{0}+b_{4 i} z_{1 i}+b_{5 i} z_{2 i}+b_{6 i} z_{3 i}+b_{7 i} z_{4 i}+u_{0 i} \\
& b_{1 i}=b_{1}+b_{8 i} z_{1 i}+b_{9 i} z_{2 i}+b_{10 i} z_{3 i}+b_{11 i} z_{4 i}+u_{1 i} \\
& b_{2 i}=b_{2}+u_{2 i} \\
& b_{3 i}=b_{3}+u_{3 i}
\end{aligned}
$$

whereby $\mathrm{z}_{1 \mathrm{i}}, \mathrm{z}_{2 \mathrm{i}}, \mathrm{z}_{3 \mathrm{i}}, \mathrm{z}_{4 \mathrm{i}}$ are a dummy variables (effect coding) of the five stands. The last conditional model will be constructed with age of the tree, diameter at breast hight (d.bh) and mean ring width per tree as impact factors (model $\mathrm{M}_{4}$ )

$$
\begin{gathered}
\text { if } \mathrm{x}_{\mathrm{ij}}<\mathrm{x}_{0 \mathrm{i}} \\
\mathrm{y}_{\mathrm{ij}}=\mathrm{b}_{0 \mathrm{i}}+\mathrm{b}_{1 \mathrm{i}} \mathrm{x}_{\mathrm{ij}}+\mathrm{b}_{2 \mathrm{i}} \mathrm{x}_{\mathrm{ij}}^{2}+\mathrm{e}_{\mathrm{ij}}
\end{gathered}
$$

otherwise

$$
y_{i j}=b_{0 i}+b_{1 i} x_{0 i}+b_{2 i} x_{0 i}^{2}+b_{3 i}\left(x_{i j}-x_{0 i}\right)+e_{i j}
$$

where

$$
\begin{aligned}
& b_{0 i}=b_{0}+b_{4 i} z_{1 i}+b_{5 i} z_{2 i}+b_{6 i} z_{2 i}+b_{7 i} z_{2 i}+u_{0 i} \\
& b_{1 i}=b_{1}+b_{8 i} z_{1 i}+b_{9 i} z_{2 i}+b_{10 i} z_{2 i}+b_{11 i} z_{2 i}+u_{1 i} \\
& b_{2 i}=b_{2}+u_{2 i} \\
& b_{3 i}=b_{3}+u_{3 i} .
\end{aligned}
$$

Different methods can be used to estimate the parameters in model (4) $[7,13,19,27]$. Here the algorithm of the SAS-MACRO "NLINMIX" Release 6.12 from Wolfinger $[37,38]$ was used. There are a few publications, which demonstrate the successful application of unconditional nonlinear mixed effects models in wood science $[14,20]$.

To sum up this discussion, the data analysis was outperformed in six steps: In the first place a suitable ringwood variable will be selected

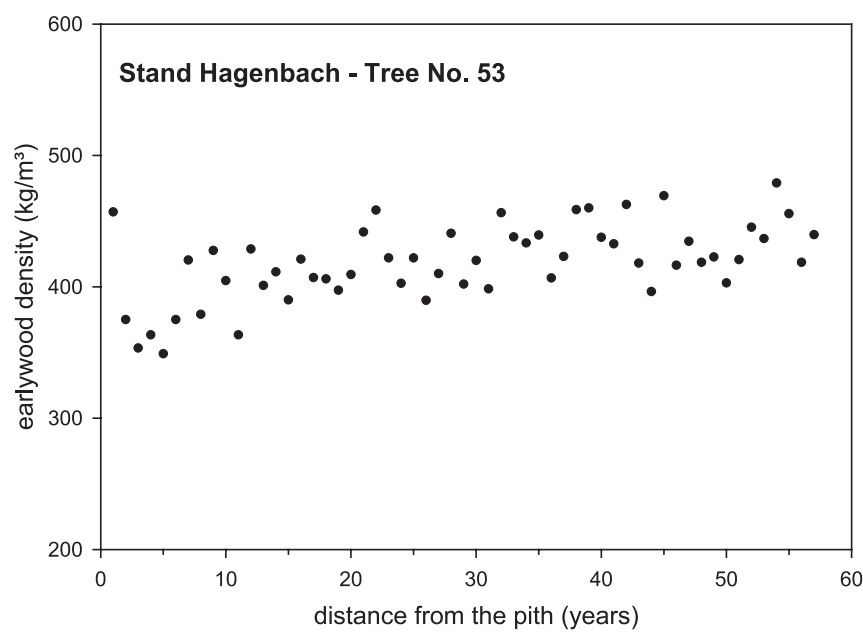

Figure 1. Earlywood density $\left(\mathrm{kg} / \mathrm{m}^{3}\right)$ in relation to age from the pith (years) for tree 53

to optimally separate mature from juvenile wood. In the second place an individual tree model shall be found to describe pith-to-bark-profiles at best for all trees, which takes into account the time-series nature of the data (Eq. (2)). In the third place the question must be answered, whether there is enough variability on the two levels of analysis (tree level vs. pith-to-bark-level) to justify a multilevel model (model $\mathrm{M}_{0}$ ). In the fourth place the unconditional nonlinear fixed-effects model (model $\mathrm{M}_{1}$ ) and mixed-effects model (model $\mathrm{M}_{2}$ ) were tested. In the final model impact factors on the tree level are added to explain the variability of the individual models (model $\mathrm{M}_{3}, \mathrm{M}_{4}, \mathrm{M}_{3 \mathrm{r}}$ ). In the final step a simulation of pith-to-bark profiles for the five stands will be done.

\section{RESULTS AND DISCUSSION}

\subsection{Search for a suitable ringwood variable as indicator of the juvenile-mature-wood- demarcation-line}

The sampling method produced usable density profiles for 99 sample trees, which included the whole range of growth rings from pith to bark. The data obtained and processed consisted of average values of ring width, mean ring density, earlywood width, earlywood density, latewood density for each growth ring. The density variables reflect the textural changes of the tracheids caused by age-dependent development of the cambium cells and thus suitable for further consideration. For each sample tree, all density variables were plotted as pith-tobark profiles and visually assessed to select a suitable indicator. The plots show more or less uniform curve patterns for the density variables (mean wood density, early wood density, late wood density). Mean wood density as earlywood density increases from pith to bark with a slightly steeper slope in the first 20 years from the pith (e.g., tree No. 83, Fig. 1). This type of curves is not suitable for a clear differentiation between juvenile and mature wood. In contrast the latewood density curves first increased rapidly for about twenty years and thereafter either remained at a relatively high density level, increased slightly, or decreased (Fig. 2). These curves make it possible to separate two different zones interpreted as juvenile and mature growth. 
Table I. Mixed-effects-model $\mathrm{M}_{0}$ : explainable variance.

\begin{tabular}{|c|c|c|c|c|}
\hline Fixed effects & & Estimate & s.e. & $t$ \\
\hline$\beta_{0}$ & & 872.27 & 5.17 & $168.68 *$ \\
\hline \multicolumn{5}{|l|}{ Random effects } \\
\hline Level 2 "Tree" & & Variance & s.e. & $z$ \\
\hline $\mathrm{u}_{0 \mathrm{j}}$ & $\sigma_{\mathrm{u} 0}^{2}$ & 1914.91 & 375.70 & $5.10^{*}$ \\
\hline \multicolumn{5}{|c|}{ Level 1 "Cambial age" } \\
\hline $\mathrm{AR}(1)$-process & $\rho$ & 0.71 & 0.008 & $88.91^{*}$ \\
\hline $\mathrm{e}_{\mathrm{ji}}$ & $\sigma_{\mathrm{e}}^{2}$ & 11003.70 & 308.97 & $35.61^{*}$ \\
\hline
\end{tabular}

s.e. $=$ standard error of the estimated parameters, $t=t$-test-value, $z=z$-test-value, $\mathrm{AR}(1)=$ first order autoregressive process. $* p<0.05$.

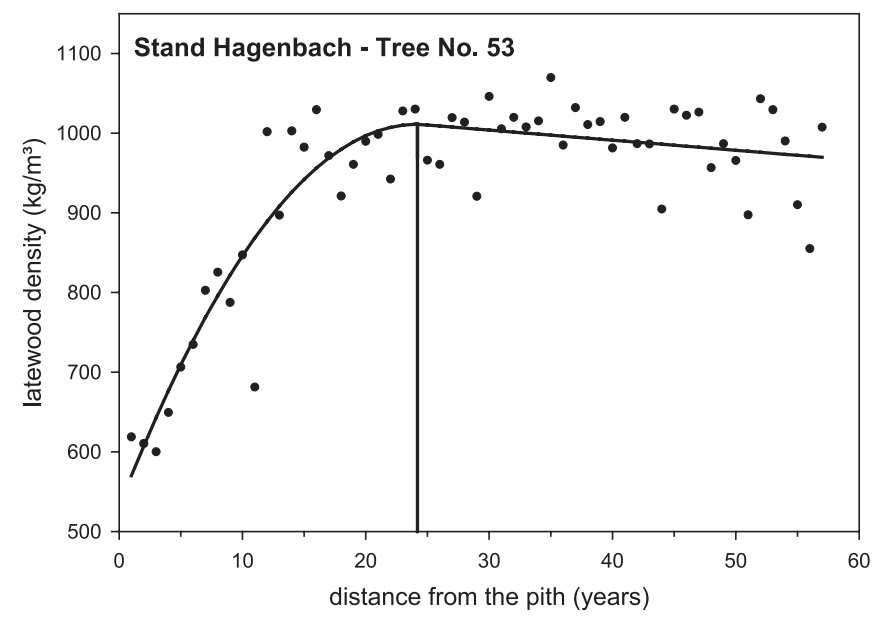

Figure 2. Latewood density $\left(\mathrm{kg} / \mathrm{m}^{3}\right)$ in relation to age from the pith (years) for tree 53. A segmented quadratic-linear model is fitted with the transition point of juvenile-mature wood as vertical line.

\subsection{Search for a suitable individual tree model}

The radial development of latewood density can be divided into two different zones. This indicates the need for two separate regressions to obtain reasonable fits for the whole profile from pith to bark: the juvenile section is best described by a quadratic curve; the mature section of the curve can be described at best with a linear function. Figure 2 illustrates the segmented regression model for one tree (tree No. 53). The segmented regression estimates simultaneously the parameters of the two combined regression function (see Eq. (1)) and the demarcation line $\mathrm{x}_{0}$. ARIMA-models are fitted preliminary for each tree. A first-order-autoregressive process of the residuals was adequate for most of the trees.

\subsection{Initial mixed-effects-model $M_{0}$ for the explainable variance}

Before mixed-effects models should be applied, it must be guaranteed at first, that there is enough variability on the different levels under consideration. Table I shows the results for the unconditional model $\mathrm{M}_{0}$ (Eq. (6)), which allows the inter- cept $b_{0 \mathrm{i}}$ to vary randomly between trees in contrast to the variability within trees [10]. An AR(1)-process was estimated with a high value of the autoregressive parameter $(\rho=0.71)$. The variance-components of $\mathrm{u}_{0 \mathrm{i}}$ und $\mathrm{e}_{\mathrm{ij}} \sigma_{\mathrm{u} 0}^{2}$ and $\sigma_{\mathrm{e}}^{2}$ summed up to the total variance, which was corrected by the autocorrelation of the residuals.

Therefore it is possible to express the variability of each level as proportion to the total variance: $14.82 \%$ of the variance of latewood density is accounted by the tree level and $85.18 \%$ by the pith-to-bark-level. In total there is enough variability on the two levels to justify the application of mixed-effects models.

\subsection{Unconditional nonlinear mixed-effects-model $\mathbf{M}_{2}$}

With nonlinear mixed-effects model the segmented regression for a single tree can be extended to the whole sample of trees, in order to estimate the demarcation line between juvenile and adult wood for the whole sample. Table II shows the result of the unconditional nonlinear-mixed-effects model (Eq. (3)). The variance of the residuals $\sigma_{\mathrm{e}}^{2}$ decreases from 11003.7 (Tab. I) in $\mathrm{M}_{0}$ to 4698.64 in $\mathrm{M}_{1}$. That means, that $57.29 \%$ of the variance of the residuals of the initial model is accounted by the nonlinear mixed-effects-model. All parameters of the fixed-effects-model, which describe the total function for the whole sample, are significant $(\alpha=0.05)$. Whereas $\beta_{0}, \beta_{1}, \beta_{2}$ characterize the juvenile part of the pith-to-bark-profile, $\beta_{3}$ describes the linear function of the adult part of the profile, here with a negative slope for all trees. Concerning the random part of the nonlinear mixed effects model only the variance components of the intercept $\sigma_{\mathrm{u} 0}^{2}$ and the linear function $\sigma_{\mathrm{u} 3}^{2}$ are significant $(\alpha=0.05)$. Finally, the demarcation between juvenile and adult wood can be derived from the estimated parameters as maximum of the quadratic function of the juvenile part: $\mathrm{x}_{0}=-\beta_{1} /\left(2 \beta_{2}\right)=-36.01 /(2-0.83)=21.69$. The juvenile-mature wood transition was determined at cambial age of about 22 years. These results give us an impression about the variability of the pith-to-bark-profiles in latewood-density: the variability of the pith-to-bark profiles between trees is high at the pith and in the adult part of the profile, represented by the intercept and the slope of the linear function. But there is no much variability between trees in the juvenile part of the profile, represented by the quadratic function of the segmented regression. Therefore it is not reasonable to construct a confidence interval of the demarcation line out of the non significant variance components. Beside of that estimating the variance of $x_{0}$ from the 
Table II. Unconditional nonlinear mixed-effects-model $\mathrm{M}_{2}$. The rows $\beta_{0}-\beta_{2}$ correspond to the first part of the fixed-effects segmented regression model (intercept, linear, quadratic trend), $\beta_{3}$ to the second part of the fixed-effects segmented regression model. The parameters of $\mathrm{u}_{0 \mathrm{i}}-\mathrm{u}_{3 \mathrm{i}}$ correspond to the variance components of the random effects. $\mathrm{AR}(1)$ is the autocorrelation coefficient.

\begin{tabular}{|c|c|c|c|c|c|c|}
\hline Fixed effects & & & & Estimate & s.e. & $t$ \\
\hline \multirow[t]{4}{*}{ Nonlinear model } & A & $\beta_{0}$ & & 548.96 & 8.07 & $67.98 *$ \\
\hline & $\mathrm{B}$ & $\beta_{1}$ & & 36.01 & 1.18 & $30.44 *$ \\
\hline & $\mathrm{C}$ & $\beta_{2}$ & & -0.83 & 0.04 & $-19.38^{*}$ \\
\hline & $\mathrm{D}$ & $\beta_{3}$ & & -1.21 & 0.12 & $-9.38 *$ \\
\hline \multicolumn{7}{|l|}{ Random effects } \\
\hline \multirow[t]{5}{*}{ Level 2 "Tree" } & & & & Variance & s.e. & $z$ \\
\hline & & $\mathrm{u}_{0 \mathrm{i}}$ & $\sigma_{\mathrm{u} 0}^{2}$ & 1936.69 & 408.25 & $4.74 *$ \\
\hline & & $\mathrm{u}_{1 \mathrm{i}}$ & $\sigma_{\mathrm{u} 1}^{2}$ & 0.91 & 2.39 & 0.38 \\
\hline & & $\mathrm{u}_{2 \mathrm{i}}$ & $\sigma_{\mathrm{u} 2}^{2}$ & 0.0048 & 0.0039 & 1.22 \\
\hline & & $\mathrm{u}_{3 \mathrm{i}}$ & $\sigma_{\mathrm{u} 3}^{2}$ & 1.052 & 0.19 & $5.43 *$ \\
\hline \multicolumn{7}{|c|}{ Level 1 "Cambial age" } \\
\hline & $\mathrm{AR}(1)$ & & $\rho$ & 0.35 & 0.01 & $32.61 *$ \\
\hline & & $\mathrm{e}_{\mathrm{ji}}$ & $\sigma_{\mathrm{e}}^{2}$ & 4698.64 & 85.41 & $55.01 *$ \\
\hline
\end{tabular}

s.e. $=$ standard error of estimated parameters, $t=t$-test-value, $z=z$-test-value, $\operatorname{AR}(1)=$ first order autoregressive process. $* p<0.05$.

Table III. Model-fit tests.

\begin{tabular}{lcccc}
\hline Model & Description & SBC & AIC & $-2 \operatorname{LogL}(\operatorname{Res})$ \\
\hline $\mathrm{M}_{0}$ & Explainable variance & -49594.0 & -49584.0 & 99161.92 \\
$\mathrm{M}_{1}$ & Fixed-effects-model & -49100.3 & -49093.3 & 98182.55 \\
$\mathrm{M}_{2}$ & Unconditional nonlinear mixed model & -48601.6 & -48580.4 & 97148.71 \\
$\mathrm{M}_{3}$ & Conditional nonlinear mixed model I & -48584.7 & -48567.0 & 97124.01 \\
$\mathrm{M}_{4}$ & Conditional nonlinear mixed model II & -48603.6 & -48586.0 & 97161.96 \\
$\mathrm{M}_{3 \mathrm{r}}$ & Final model (revised model $\mathrm{M}_{3}$ ) & -48570.9 & -48553.2 & 97096.49 \\
\hline
\end{tabular}

SBC = Schwarz's Bayesian Criterion, AIC = Akaike's Information Criterion, $-2 \log L(\operatorname{Res})=-2 \times \log$ likelihood of the residuals.

variance components of a ratio term is only possible under certain conditions. Furthermore it can be stated, that there is a significant autocorrelation of the residuals about $\rho=0.35$.

\subsection{Conditional nonlinear mixed-effects model $M_{3}$, $M_{4}, M_{3 r}$}

Nonlinear mixed-effects models provide not only unbiased consistent estimates of the demarcation line, but also possibilities to examine the impacts of several tree variables on the variability of pith-to-bark curves, respectively on the variability of the transition between juvenile and adult wood. Two such conditional models $\left(\mathrm{M}_{3}, \mathrm{M}_{4}\right)$ are examined. The first one tests the impact of the stand effects on the shape of the pith-to-bark profiles (see Eq. (7)), the second one examines the impact of age of the tree, diameter at breast height (d.bh) and mean ring width per tree on latewood-density curves (see Eq. (8)). The variance component of $\sigma_{\mathrm{u} 1}^{2}$ was set to zero, because it is not significant. Afterwards the variance-component $\sigma_{\mathrm{u} 2}^{2}$ will be significant.

Table III shows the different mixed effects models, which are compared using three different information criteria: the
Schwarz's bayesian criterion (SBC), the Akaike information criterion (AIC) and the negative doubled loglikelihood of the residuals [10]. The Akaike information criterion appears to be the criterion of choice to compare models with alternative suites of fixed-effects and variance-component-parameters. The greater the value of these criteria, the better the model fits. The initial model $\mathrm{M}_{0}$ and the model $\mathrm{M}_{1}$, which only includes the fixed-effects and won't be treated further, are worse than the following unconditional or conditional models. If one have to decide between conditional model $\mathrm{M}_{3}$ and $\mathrm{M}_{4}$, one have to prefer conditional model $\mathrm{M}_{3}$ due to its higher values in SBC, AIC and loglikelihood-value. This significance demonstrates the great impact of the stand factor on the shape of the pith-tobark-curves in comparison to the impact of tree age, mean ring width and diameter at breast height. More precisely the stand factor has statistically significant impact on the intercept of the pith-to-bark-profiles and on the slope of the linear function in the adult wood zone of the curve. Therefore the revised model $\mathrm{M}_{3 \mathrm{r}}$ consists only of the significant parts of model $\mathrm{M}_{3}$. As Table IV shows, all parameters of the nonlinear fixed effectsmodel $\beta_{0}-\beta_{3}$ are significant. The point of transition between juvenile and adult wood for the whole sample can be derived 
Table IV. Final conditional nonlinear mixed-effects-model $\mathrm{M}_{3 \mathrm{r}}$. The rows $\beta_{0}-\beta_{3}$ correspond to the fixed-effects segmented regression model (intercept, linear, quadratic trend, linear slope), $\beta_{4}-\beta_{7}$ to the fixed-effects of the stand factor, $\beta_{8}-\beta_{11}$ to the interaction stand factor $\times$ linear slope of the segmented regression. The parameter $\mathrm{u}_{0 \mathrm{i}}-\mathrm{u}_{3 \mathrm{i}}$ are the corresponding random effects. $\mathrm{AR}(1)$ is the autocorrelation coefficient.

\begin{tabular}{|c|c|c|c|c|c|c|}
\hline Fixed effects & & & & Estimate & s.e. & $t$ \\
\hline \multirow[t]{4}{*}{ Nonlinear model } & A & $\beta_{0}$ & & 548.61 & 7.99 & $68.67 *$ \\
\hline & $\mathrm{B}$ & $\beta_{1}$ & & 36.14 & 1.19 & $30.40 *$ \\
\hline & $\mathrm{C}$ & $\beta_{2}$ & & -0.83 & 0.04 & $-19.19 *$ \\
\hline & $\mathrm{D}$ & $\beta_{3}$ & & -1.14 & 0.12 & $-9.65^{*}$ \\
\hline \multirow[t]{4}{*}{ Stands } & 1 & $\beta_{4}$ & & 19.00 & 9.87 & 1.93 \\
\hline & 2 & $\beta_{5}$ & & -18.98 & 9.70 & -1.96 \\
\hline & 3 & $\beta_{6}$ & & -23.24 & 9.73 & $-2.39^{*}$ \\
\hline & 4 & $\beta_{7}$ & & 19.00 & 9.69 & $1.96^{*}$ \\
\hline \multirow[t]{4}{*}{ Stands $\times D$} & 1 & $\beta_{8}$ & & 0.51 & 0.22 & $2.36^{*}$ \\
\hline & 2 & $\beta_{9}$ & & 0.002 & 0.206 & 0.01 \\
\hline & 3 & $\beta_{10}$ & & 0.35 & 0.28 & 1.24 \\
\hline & 4 & $\beta_{11}$ & & 0.02 & 0.22 & 0.11 \\
\hline \multicolumn{7}{|l|}{ Random effects } \\
\hline \multirow[t]{4}{*}{ Level 2 "Tree" } & & & & Variance & s.e. & $z$ \\
\hline & & $\mathrm{u}_{0 \mathrm{i}}$ & $\sigma_{\mathrm{u} 0}^{2}$ & 1772.50 & 327.90 & $5.41^{*}$ \\
\hline & & $\mathrm{u}_{2 \mathrm{i}}$ & $\sigma_{\mathrm{u} 2}^{2}$ & 0.0064 & 0.0016 & $3.95^{*}$ \\
\hline & & $\mathrm{u}_{3 \mathrm{i}}$ & $\sigma_{\mathrm{u} 3}^{2}$ & 0.827 & 0.157 & $5.27 *$ \\
\hline \multicolumn{7}{|c|}{ Level 1 "Cambial age" } \\
\hline & $\operatorname{AR}(1)$ & & $\rho$ & 0.35 & 0.01 & $32.73 *$ \\
\hline & Residual & $\mathrm{e}_{\mathrm{ji}}$ & $\sigma_{\mathrm{e}}^{2}$ & 4699.80 & 85.18 & $55.17 *$ \\
\hline
\end{tabular}

s.e. $=$ standard error of estimated parameters, $t=t$-test-value, $z=z$-test-value, $\operatorname{AR}(1)=$ first order autoregressive process. ${ }^{*} p<0.05$.

as mentioned above: $x_{0}=-\beta_{1} /\left(2 \quad \beta_{2}\right)=-36.14 /(2-0.83)=$ 21.77. It cannot be found any significant impacts of stands on the parameters $\beta_{1}, \beta_{2}$. In other words there are no sharply different transition zones between stands.

However, the pith-to-bark-profiles show for each stand different shapes of curves, especially different starting points (intercept) and different slopes in the adult zone, represented by the significant parameters $\beta_{4}-\beta_{1}$ : due to the effect-coding of the stand effects the parameter $\beta_{0}$ represents the starting point of the mean pith-to-bark-profile for the whole sample $\left(548.61 \mathrm{~kg} / \mathrm{m}^{3}\right)$, whereas the latewood density at the pith of stand 1 and 4 exceeds this intercept about $19 \mathrm{~kg} / \mathrm{m}^{3}$, the latewood density at the pith of stand 2 ( 3 and 5) falls below this intercept about $-18.98 \mathrm{~kg} / \mathrm{m}^{3}\left(-23.24 \mathrm{~kg} / \mathrm{m}^{3}-4.22 \mathrm{~kg} / \mathrm{m}^{3}\right)$.

If one adds the parameters for each stand $\beta_{8}-\beta_{11}$ to the slope parameter $\beta_{3}$ one get the slope for each stand: -0.63 (stand 1 ); -1.14 (stand 2); -0.079 (stand 3$) ;-1.12$ (stand 4); -1.14 (stand 5). Firstly, all stands show on average decreasing latewood density in the adult zone, indicated by a negative slope for each stand. Secondly, in contrast to stands 2, 4 and 5 with a sharp decrease in latewood density in the adult zone, stand 1 and 3 show rather flat curves in this pith-to-bark-area, whereas stand 3 represents slightly better growth conditions than the other ones.

Until now we assumed implicitly that there are no variability of pith-to-bark-curves within stands, respectively between trees in stand. This assumption cannot be maintained consid- ering the random effects-part of the mixed-effects model $\mathrm{M}_{3 \mathrm{r}}$ : the model yields still significant variance components of the random effects of the intercept $\left(\sigma_{\mathrm{u} 0}^{2}=1772.5\right)$, of the quadratic part of the segmented regression $\left(\sigma_{\mathrm{u} 2}^{2}=0.0064\right)$ and the linear slope in the adult zone $\left(\sigma_{\mathrm{u} 3}^{2}=0.827\right)$, although stand effects are included in the model. These variance components allow us not only to calculate a shell, in which individual pith-to-bark-profiles can be met at a certain probability as electrons within the shell of an atomic nucleus, but also to define a confidence interval for the transition point $x_{0}=\beta_{1} /\left(2 \beta_{2}\right)$. In the following the concept of "confidence interval" is not quite understood in its classical sense as standard error of parameters, but in the sense of variability of parameters between individuals, here trees.

The variability of the transition point $\mathrm{x}_{0}$ can be defined as a division between two variables $\mathrm{x}_{0}+\mathrm{u}_{\mathrm{x} 0}=\left(\beta_{1}+\mathrm{u}_{1}\right) /\left(2\left(\beta_{2}+\mathrm{u}_{2}\right)\right)$, whereby $\mathrm{u}_{\mathrm{x} 0}, \mathrm{u}_{1}$ and $\mathrm{u}_{2}$ are random effect-variables, normally distributed. Generally it is not possible to derive a valid estimate of the variance components $\sigma_{\mathrm{ux} 0}^{2}$ from the division of two variables. However under certain conditions a confidence interval of the point of transition can be estimated. In this special case only the variance component of $\mathrm{u}_{2}$ is significant and has to be considered. Therefore it is possible to define a $95 \%$-confidenceinterval for the random effect $\mathrm{u}_{2}: \pm 1.96 \sqrt{0.0064}= \pm 0.1568$. The quadratic parameter varies at a probability of $95 \%$ from $\beta_{2}$ $-0.1568=-0.9868$ till $\beta_{2}+0.1568=-0.673$ between trees. Finally, a $95 \%$-confidence interval of the transition point $\mathrm{x}_{0}$ can 
be calculated as follows $\left[\mathrm{x}_{0}=-36.14 /(2-0.9868) ; \mathrm{x}_{0}=-36.14 /\right.$ $(2-0.673)]=[18.31 ; 26.85]$.

Last but not least, one can compare the variance components of $u_{0}$ and $u_{3}$ of model $M_{2}$ (Tab. III) with the components of $M_{3 r}$ to estimate the size of impact of the stand factor on the variability of pith-to-bark profiles. The variability of the intercept of model $\mathrm{M}_{2}$ decreases from $\sigma_{\mathrm{u} 0}^{2}=1936.69\left(\mathrm{M}_{2}\right)$ to $\sigma_{\mathrm{u} 0}^{2}=1772.5\left(\mathrm{M}_{3 \mathrm{r}}\right)$. In other words, $8.5 \%$ of the variability of the intercepts $\mathrm{u}_{0}$ and $21.3 \%(=(1.052-0.827) / 1.052)$ of the variance of the linear slope in the adult zone $\mathrm{u}_{3}$ is explained by stand effects.

\subsection{Simulation}

After improving the model and its fitting with our data, the last stage was to include them in a growth simulator. Mixedeffects-model offer the great opportunity for simulation: The fixed-effects model yields the mean tendency, the random effect model with the matrix of the variance-covariance components result in several possible tendencies within the population. Here this variance-covariance-matrix is used for two objectives. Firstly, a 95\%-confidence interval of pith-to-bark profiles per tree can be created for each stand, to represent the amount of variability of pith-to-bark-profiles of each stand in comparison to the mean profile of latewood density. If the covariances of the parameters are neglected $\left(\sigma_{01}=\sigma_{02}=\sigma_{12}=0\right)$, the total variance of random effects can be easily estimated with respect to the estimated parameter $\sigma_{\mathrm{u} 0}^{2}, \sigma_{\mathrm{u} 2}^{2}, \sigma_{\mathrm{u} 3}^{2}$ and $\mathrm{x}_{0}$ in Table IV, as follows:

$$
\begin{gathered}
\text { if } \mathrm{x}_{\mathrm{ij}}<\mathrm{x}_{0} \\
\operatorname{var}\left(\mathrm{u}_{0 \mathrm{i}}+\mathrm{u}_{2 \mathrm{i}} \mathrm{x}_{\mathrm{ij}}{ }^{2}\right)=\sigma_{\mathrm{u} 0}^{2}+\sigma_{\mathrm{u} 2}^{2} \mathrm{x}_{\mathrm{ij}}^{4}=1772.5+0.0064 \mathrm{x}_{\mathrm{ij}}^{4}
\end{gathered}
$$

otherwise

$$
\begin{gathered}
\operatorname{var}\left(\mathrm{u}_{0 \mathrm{i}}+\mathrm{u}_{2 \mathrm{i}} \mathrm{x}_{0}^{2}+\mathrm{u}_{3 \mathrm{i}}\left(\mathrm{x}_{\mathrm{ij}}-\mathrm{x}_{0}\right)\right)=\sigma_{\mathrm{u} 0}^{2}+\sigma_{\mathrm{u} 2}^{2} \mathrm{x}_{0}^{4}+\sigma_{\mathrm{u} 3}^{2}\left(\mathrm{x}_{\mathrm{ij}}-\mathrm{x}_{0}\right)^{2} \\
=1772.5+0.006421 .77^{4}+0.827\left(\mathrm{x}_{\mathrm{ij}}-21.77\right)^{2} .
\end{gathered}
$$

The $95 \%$-confidence interval as a shell of the pith-to barkprofiles around the mean curve of a stand, derived by the fixedeffects-model, is defined as $\pm 1.96 \sqrt{\mathrm{var}}$. Figure 3 (a-e) shows for each stand the mean predicted curve, the $95 \%$-confidenceinterval of pith-to-bark profiles and the point of transition from juvenile to adult wood and its confidence interval. As mentioned above only significant differences between stands in the starting point of the mean curve and the slope in the adult zone can be observed. Therefore the curves look very similar. Nevertheless stand Dahn I, Elmstein-South I and II show higher intercepts of the curves $\left(\sim 600 \mathrm{~kg} / \mathrm{m}^{3}\right)$. Among all ElmsteinSouth II shows the sharpest negative slope in the adult zone.

Secondly, the matrix of the variance-covariance-components serves not only for confidence intervals, but also for the possibility of a simulation of pith-to-bark-profiles of the same population from which the sample was drawn. For each equation constructed with mixed effects model procedure, we had to generate values of parameters (for example $\mathrm{u}_{0}, \mathrm{u}_{2}$ ) from normal distribution with mean 0 and the given variance-covariance-matrix $\mathrm{V}$, whereby the covariances are fixed to zero.
Firstly, we generated a random vector $\mathrm{g}$ from a normal distribution with mean 0 and identity variance-covariance-matrix, using the SAS-function "Normal". Secondly, g is transformed to a $N(0, V)$ by multiplying it by a lower triangular matrix $L$ such that L'L $=\mathrm{V}$ (Cholesky-decomposition with SAS-IML-function "root") [21]. To obtain a single pith-to-bark profile of a stand one vector of random components $\mathrm{u}_{0}, \mathrm{u}_{2}$ and $\mathrm{u}_{3}$ was drawn from this sample and added to the fixed effects parameters of $\beta_{0}, \beta_{2}$ and $\beta_{3}$, respectively for each stand.

On the last stage the residuals had to be simulated. As mentioned above a random variable with known distribution and error variance was constructed. With respect to the first order autoregressive process a corresponding $\Omega$-Matrix, derived from the estimated autoregressive parameter, serves to transform the generated random variable to the residuals with the known autocorrelation structure [33]. The result of this growth-simulation is displayed in Figure $3(\mathrm{f}-\mathrm{j})$. Such individual pith-tobark-profiles deviate slightly from the mean profile of the stand, but stay within the confidence-interval of the stand profiles with a probability of 0.95 . Certain waves in the residuals are quite apparently picturing the autocorrelated data.

\section{DISCUSSION}

The point at which the transition from juvenile to mature wood occurs is a central issue affecting wood quality and product value. However, to estimate this boundary with sufficient reliability is difficult. One reason for this difficulty is that some species as spruce (Picea spp.) or cypress(Cupressus spp.) show indistinct juvenile-mature transition zone, some show clear transition from juvenile to mature wood as Douglas-fir and Hard pines. Another reason is, that there are missing appropriate statistical methods to obtain consistent, efficient and reliable estimates of the transition point parameter. Until now segmented regression models were used to estimate $[1,5,9,11$, 33 ] the transition point. However this method suffers from estimating the demarcation line between juvenile and adult wood for each tree separately without any consideration about statistical distributions.

The nonlinear mixed-effects-model discussed in the present paper try to overcome this limitation while retaining a comparative simplicity and interpretability that we hope will contribute to its adoption by others. It is now possible to derive efficient and consistent estimates for the transition point in a population from a sample drawn from that population, whereby the timeseries nature of the data can be taken into account. Concerning the investigated sample of 99 Scots pine the mean transition point as consistent estimate of the population value estimation is 21.77 year. One can estimate the standard error and confidence-interval for the transition point. In this case the transition points vary with the probability of $95 \%$ within the interval of $[18.31 ; 26.85]$. But there is thus far no general mathematical solution to estimate the standard error of a division out of the standard errors of the parameters of the division.

Furthermore one cannot make any general inferences concerning Scots pine, because there is missing a sampling strategy, which takes random samples from the full range of Scots pine population. Additionally, the design of the study, which 

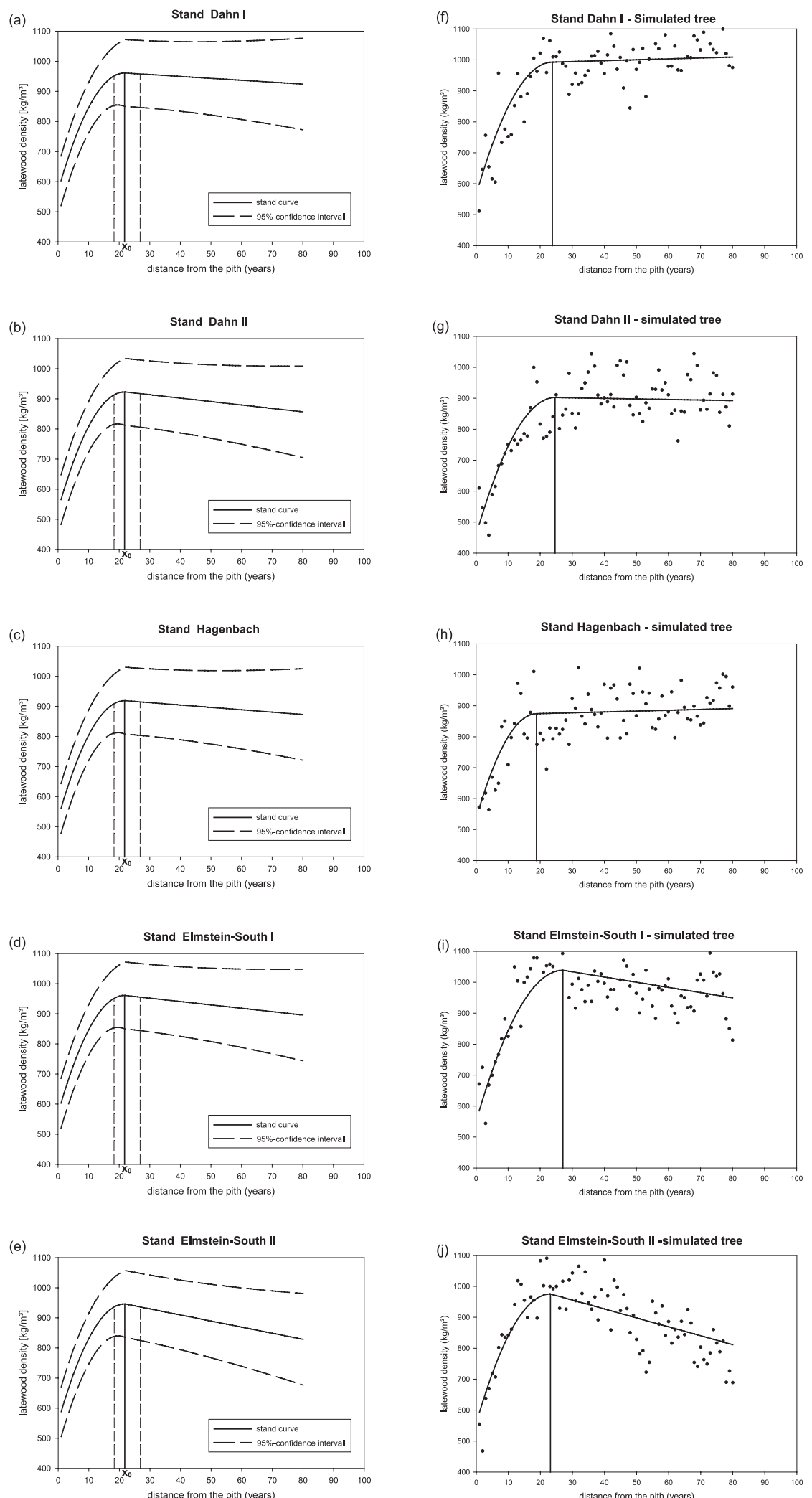

Figure 3. Simulation of mean pith-to-bark profiles for stands (a-e) and for single trees $(\mathrm{f}-\mathrm{j})$. For each stand a stand curve is fitted with the $95 \%$-confidence interval for the predicted individual profiles as dotted lines, the transition point $\mathrm{x}_{0}$ as vertical line and its $95 \%$-confidence interval as dotted vertical line $(\mathrm{a}-\mathrm{e})$. For a sampled tree the segmented regression model is fitted with the transition point as vertical line and the simulated individual values as dots $(\mathrm{f}-\mathrm{j})$. 
focus on the most usable and valuable wood, allowed only to take disks from one height $(4 \mathrm{~m})$. Therefore the estimated transition point is restricted to this height.

The suggested method offers the possibility to test whether the stand factor or properties of trees (f. ex. d.bh., tree age) have any impact on the sample variability of the parameters, especially on the location of the point of juvenile-mature-woodtransition. Certain information criteria allow to evaluate and compare different models, to select the best fitting one. Here we do not find any significant impact of age of the tree, diameter at breast height (d.bh) and mean ring width per tree on latewood-density curves. Only the stand factor has certain impacts on the beginning of the pith-to-bark-profiles and on the linear slope in the adult zone. Around $8.5 \%$ of the variability of the intercepts and $21.3 \%$ of the variance of the linear slope in the adult zone is explained by the stand factor. The location of the transition between juvenile and adult zone does not vary between stands.

The estimated random and fixed effects allows a simulation of pith-to-bark profiles, which are sampled from the same population as the observed sample, which can be used as growth simulator. The statistic-software SAS offers the possibility to calculate nonlinear mixed-effects models either with the MACRO NLINMIX or the new procedure PROC NLINMIX in the actual release. In S-PLUS procedure for nonlinear mixedeffects models belongs to the standard equipment.

To sum up, we can say, that nonlinear mixed effects models allow not only to estimate consistently and efficiently the juvenile-mature wood transition point for a population, but also make it possible to test, whether there are significant differences between pith-to-bark-curves and whether this variability can be explained by certain tree or stand variables. The estimation procedure simultaneously take into account the time-series nature of the data. The results can be used for simulation of tree growth as one element of a forest management system.

\section{REFERENCES}

[1] Abdel-Gadir A.Y., Krahmer R.L., Estimating the age of demarcation of juvenile and mature wood in Douglas-fir, Wood Fiber Sci. 25 (1993) 242-249.

[2] Bendtsen B.A., Senft J.F., Mechanical and anatomical properties in individual growth rings of plantation grown cottonwood and loblolly pine, Wood Fiber Sci. 18 (1978) 23-28.

[3] Bhat K.M., Priya P.B., Rugmini P., Characterisation of juvenile wood in teak, Wood Sci. Technol. 34 (2001) 517-532.

[4] Box G.E.P., Jenkins G.M., Time series analysis, San Francisco, $1970,553 \mathrm{p}$.

[5] Cook J.A., Barbour R.J., The use of segmented regression analysis in the determination of juvenile and mature wood properties, Reports CFS No. 31, Forintek Canada, Corp., Vancouver, BC, $1989,53 \mathrm{p}$

[6] Danborg F., Density variations and demarcation of the juvenile wood in Norway spruce, Forskningsserien No.10-1994, Danish Forest and Landscape Research Institute, Lyngby, 1994, 78 p.

[7] Davidian M., Giltinan D.M., Nonlinear models for repeated measurement data, London, 1995, $359 \mathrm{p}$.

[8] Degron R., Nepveu G., Prévision de la variabilité intra- et interabre de la densité du bois de Chêne rouvre (Quercus petraea Liebl.) par modélisation de largeurs et des densités des bois initial et final en fonction de l'âge cambial, de la largeur de cerne et du niveau dans l'arbre, Ann. Sci. For. 53 (1996) 1019-1030.

[9] Di Lucca C.M., Juvenile-mature wood transition, in: Kellogg R.M., Second growth Douglas-fir: Its management and conversion for value, Special Publication, No. Sp-32, Forintek, Canada Crop., Vancouver, 1989, $173 \mathrm{p}$.

[10] Engel U., Einführung in die Mehrebenenalyse, Opladen, 1998 , $280 \mathrm{p}$.

[11] Evans J.W., Senft J.F., Green D.W., Juvenile wood effect in red alder: analysis of physical and mechanical data to delineate juvenile and mature wood zones, For. Prod. J. 50 (2000) 75-87.

[12] Gallant A.R., Nonlinear statistical models, New York, 1987, 610 p.

[13] Goldstein H., Nonlinear multilevel models with an application to discrete response data, Biometrics 78 (1991) 45-51.

[14] Gregoire T.G., Schabenberger O., Barrett J.P., Linear modelling of irregularly spaced, unbalanced, longitudinal data from permanentplot measurements, Can. J. For. Res. 25 (1995) 137-156.

[15] Guilley E., Hervé J.-C., Huber F., Nepveu G., Modelling variability of within-ring density components in Quercus petraea Liebl. with mixed-effect models and simulating the influence of contrasting silviculture on wood density, Ann. For. Sci. 56 (1999) 449-458.

[16] Koubaa A., Zhang S.Y.T., Makni S., Defining the transition from early wood to latewood in black spruce based on intra-ring wood density profiles from X-ray densitometry, Ann. For. Sci. 59 (2002) 511-518.

[17] Krahmer R.L., Fundamental anatomy of juvenile and mature wood, in: Proc. Technical Workshop: Juvenile wood - What does it mean to forest management and forest products? For. Prod. Res. Soc. Madison, 1986, $56 \mathrm{p}$.

[18] Kucera B., A hypothesis relating current annual height increment to juvenile and wood formation in Norway spruce, Wood Fiber Sci. 26 (1994) 152-167.

[19] Lindstrom M.J., Bates D.M., Nonlinear mixed effects models for repeated measures data, Biometrics 46 (1990) 673-687.

[20] Maguire D.A., Johnston S.R., Cahill J., Predicting branch diameters on second growth Douglas-fir from tree-level descriptors, Can. J. For. Res. 29 (1999) 1829-1840.

[21] Meredieu C., Colin F., Hervé J.-C., Modelling branchiness of Corsican pine with mixed-effects models (Pinus nigra Arnold ssp. laricio (Poiret) Maire), Ann. For. Sci. 55 (1998) 359-374.

[22] Mörling T., Evaluation of annual ring width and ring density development following fertilisation and thinning of Scots pine, Ann. For. Sci. 59 (2002) 29-40.

[23] Mork E., Die Qualität des Fichten-Holzes unter Rücksichtnahme auf Schleif/Papierholz, Der Papier-Fabrikant 26 (1928) 741-747.

[24] Mothe F., Duchanois G., Zanier B., Leban J.M., Analyse microdensitométrique appliquée au bois: méthode de traitement des données utilisées à l'INRA-ERQB (programme CERD), Ann. Sci. For. 55 (1998) 301-313.

[25] Mutz R., Inhomogenität des Roh- und Werkstoffs Holz. Konzeptuelle, methodisch-statistische und empirische Implikationen für holzkundliche Untersuchungen, Hamburg, 1998, 336 p.

[26] Panshin A.J., de Zeeuw C., Textbook of Wood Technology, 4th ed. New York, 1980, 452 p.

[27] Pinheiro J.C., Bates D.M., Approximations to the log-likelihood function in the nonlinear mixed-effects model, J. Comp. Graph. Stat. 4 (1995) 12-35.

[28] Polge H., Établissement des courbes de variation de la densité du bois par exploration densitométrique de radiographies d'échantillons prélevés à la tarière sur des arbres vivants, Ann. Sci. For. 23 (1966) 1-206.

[29] Polge H., Fifteen years of wood radiation densitometry, Wood Sci. Technol. 12 (1978) 187-196.

[30] Rendle B.J., Fast-grown coniferous timber - some anatomical considerations. Q. J. For. (1959) 1-7.

[31] Rendle B.J., Juvenile and adult wood, J. Inst. Wood Sci. 5 (1960) $58-61$. 
[32] Sauter U.H., Technologische Holzeigenschaften der Douglasie (Pseudotsuga menziesii (Mirb.) Franco) als Ausprägung unterschiedlicher Wachstumsbedingungen. Dissertation an der Forstwiss. Fakultät der Universität Freiburg, 1992, 221 p.

[33] Sauter U.H., Mutz R., Munro B.D., Determining juvenile-mature wood transition in Scots pine using latewood density, Wood Fiber Sci. 31 (1999) 416-425.

[34] Schweingruber F., Der Jahrring: Standort, Methodik, Zeit und Klima in der Dendrochronologie, Bern, 1983, 234 p.

[35] Wilhelmson L., Arlinger J., Spangeberg K., Lundquist S.-O., Grahn T., Hedenberg Ö., Olsson L., Models for predicting wood properties in stems of Picea abies and Pinus sylvestris in Sweden, Scand. J. For. Res. 17 (2002) 330-350.

[36] Wimmer R., Geoffrey M.D., Evans R., High resolution analysis of radial growth and wood density in Eucalyptus nitens, grown under different irrigation regimes, Ann. For. Sci. 59 (2002) 519-524
[37] Wolfinger R.D., Laplace's approximation for nonlinear mixed models, Biometrika 80 (1993) 719-795.

[38] Wolfinger R.D., Fitting nonlinear mixed models with the new NLMIXED procedure, SAS Institute, Inc., Cary, N.C. No. 287, $1999,120 \mathrm{p}$.

[39] Zhang S.Y., Eyono Owundi R., Nepveu G., Mothe F., Dhôte J., Modelling wood density in European oak (Quercus petraea and Quercus robur) and simulating the silvicultural influence, Can. J. For. Res. 23 (1993) 2587-2593.

[40] Zhu-Jian J., Nakano T., Hirakawa Y., Zhu J.J., Effects of radial growth rate on selected indices of juvenile and mature wood of the Japanese larch, J. Wood Sci. 46 (2000) 417-422.

[41] Zobel B.J., Van Buijtenen J.P., Wood Variation. Its causes and control, Heidelberg, 1989.

[42] Zobel B.J., Tabert J.B., Applied forest tree improvement, New York, 1984.

To access this journal online: www.edpsciences.org 